\title{
Universiteit
}

Leiden

The Netherlands

\section{Hypnosis in the treatment of conversion and somatization disorders}

Moene, F.; Roelofs, K.; Nash M.R., Barnier A.J.

\section{Citation}

Moene, F., \& Roelofs, K. (2008). Hypnosis in the treatment of conversion and somatization disorders. In B. A. J. Nash M.R. (Ed.), The Oxford Handbook of Hypnosis. (pp. 625-645).

Oxford: Oxford University Press. Retrieved from https://hdl.handle.net/1887/14252

Version: $\quad$ Not Applicable (or Unknown)

License: $\quad$ Leiden University Non-exclusive license

Downloaded from: https://hdl.handle.net/1887/14252

Note: To cite this publication please use the final published version (if applicable). 


\section{The Oxford Handbook of}

Hypnosis

\section{Theory, Research and Practice}

Edited by

\section{Michael R. Nash}

Psychology Department, University of Tennessee, Knoxville, TN, USA

\section{Amanda J. Barnier}

Macquarie Centre for Cognitive Science,

Macquarie University, Sydney, NSW, Australia 
A., Tope, D. M. and Burish, T. G. raction and relaxation training for ects due to caner chemotherapy, Medicine, 16: 65-80.

imidt, F. (1992) A meta-analytic fectiveness of smoking cessation Ipplied Psychology, 77: 554-561. and Faragher, E. B. (1984) pnotherapy in the treatment of table-bowel syndrome. Lancet,

and Colgan, S. M. (1987)

ere irritable-bowel syndrome. Gut,

C., Siegler, I. C., Eigenbrodt, M. L., er, H. A. (2000) Anger proneness art disease risk: prospective analysis osis risk in communities (ARIC) 1: 2034-2039.

s. E., Wells and V. E. (1999)

of the mortality of depression.

ine, 61: 18-20.Wulsin, L. R.

S., Murabito, J. M., Kelly-Hayes, J. (2005) Depressive symptoms, se, and overall mortality in the tudy. Psychosomatic Medicine, 67:

S. (1982) Hvpnosis and nonhypnotic tion of pain and anxiety during in children and adolescents with diatiatrics, 101: 1032-1035.

X. J., LeBaron, S. and LeBaron, C. $d$, controlled study of behavioral motherapy distress in children with 3: 34-42.

\title{
CHAPTER 26
}

\section{Hypnosis in the treatment of conversion and somatization disorders}

\author{
Franny C. Moene and Karin Roelofs
}

\subsection{Domain of the problem}

Conversion disorder $(\mathrm{CD})$ refers to the presence of deficits affecting the voluntary motor or sensory functions. These symptoms suggest neurological or other organic causes, but are believed to be associated with psychological stressors (American Psychiatric Association, 1994). Conversion and somatization symptoms were initially described in the context of hysteria, and have always been subject to debate and conceptual confusion. That this debate is still alive is reflected in the manner in which the disorder is currently classified within the two major current nosologies: in the DSM-IV (American Psychiatric Association, 1994) CD is a type of somatoform disorder; In the ICD-10 (World Health Oraganization, 1992) it is a dissociative disorder. For convenience, we follow the DSM-IV criteria, although in our theoretical review we present arguments for a dissociative classification.

Neurological symptoms for which no adequate physiological explanation can be found can be subsumed not only under the diagnosis of $\mathrm{CD}$, but also under the diagnosis of somatization disorder (SD). Aside from differences in symptom numbers and illness chronicity, the available data indicate that there is little that distinguishes
CD from SD (Ron, 2001; Wade, 2001; Brown, 2004). We focus on CD, with the notion that most of the described features and treatment models apply to both CD and SD.

The presentation of conversion symptoms mimics a broad spectrum of neurological diseases. The most common conversion symptoms are motor symptoms, such as paralysis, incoordination, ataxia and tremor. The second most common symptom cluster consists of somatosensory symptoms that may involve anesthesia, blindness and sometimes deafness. Another cluster of symptoms may involve seizure-like activity. There can also be a mixed presentation in which there are motor symptoms, sensory and seizure-like symptoms.

According to the DSM-IV criteria of CD, the onset or exacerbation of these symptoms has to be associated with psychological stress or trauma. Childhood sexual, physical and emotional abuse have indeed been linked to conversion and somatization symptoms (e.g. Morrison, 1989; Betts and Boden, 1992; Alper et al., 1993; Binzer and Eisemann, 1998; Kuyk et al., 1999; Litwin and Cardeña, 2000; Roelofs et al., 2002a; Salmon et al., 2003; Brown et al., 2005) Further, it is not uncommon for conversion symptoms to develop following exposure to acute stressors 
(Binzer et al., 1997; Roelofs et al., 2005). Nevertheless, several authors have questioned the necessity of identifying psychosocial precipitants in order to make a firm diagnosis of CD or SD (e.g. Merskey, 1979; Ron, 1994). Although clear environmental precursors are often found, they can be absent in some cases (Ron, 1994; Roelofs et al., 2002a).

Psychiatric co-morbidity is common in CD. Axis-1 (DSM-IV) co-morbidity, mainly of depression and anxiety disorders, is observed in 22-75 per cent of the patients (Mace and Trimble, 1996; Binzer et al., 1997; Crimlisk et al., 1998). Personality disorders are observed in 37-59 percent of the patients (Binzer et al., 1997; Crimlisk et al., 1998; Moene et al., 2001; Roelofs et al., 2002b). In some of these studies, histrionic personality disorders have been observed, but other types of disorders such as dependent personality disorder are far more common. The co-morbidity rates of neurological disorders largely depend on the treatment setting. Whereas approximately 50 percent of the patients in neurological settings show neurological co-morbidity (Marsden, 1986; Factor et al., 1995), only 3 percent of the patients in psychiatric settings were identified to have additional neurological disorders (Roy, 1979).

Despite the difficulties of excluding neurological disease and malingering, $\mathrm{CD}$ can be diagnosed with a fair amount of reliability provided standard diagnostic protocols are carefully followed (e.g. Crimlisk et al., 1998; Halligan et al., 2001). This view was recently supported by two neurophysiological studies showing differential neurophysiological correlates for CD and malingering in cases of sensory (Lorenz et al., 1998) and motor loss (Spence et al., 2000), respectively.

\subsection{Theoretical models}

Despite the variety of manifestations of conversion symptoms, the symptoms share one important feature, i.e. the CD patient's symptom presentation is observably altered by environmental and social influences, yet the patient remains unaware of it. There appears to be a disconnection between conscious experience or knowledge and implicit automatic or procedural knowledge (Kihlstrom, 1992). For example, Bryant and McConkey (1989) showed that patients with conversion blindness could modify their behavior in response to visual information they deny seeing. Yet they remain oblivious to this strategy. Sackheim et al. (1979) proposed that hysterically blind patients performed differently on a visual task depending on whether or not the visual task was presented as a test for blindness. In a clinical setting, we observed a patient who claimed to have no visual awareness of his immediate environment, but who was reasonably able to maneuver through an examination room without bumping into the furniture. In the case of conversion paralysis, a conversion patient is unable to move one or more parts of the body intentionally. Under less controlled or intentional circumstances such as during sleep (Lauerma, 1993) or hypnosis (Moene et al., 1998) the patient may, however, show some movement with the affected area. Ziv et al. (1998) clearly demonstrated this phenomenon by testing the involuntary extension of an affected leg when voluntarily flexing the contralateral (normal functioning) leg against resistance. Compared with healthy controls and patients with neurological weakness, patients with conversion paralysis showed significantly more involuntary than voluntarily limb contractions with the affected limb. These discrepancies between explicit (voluntary) and implicit (involuntary) motor as well as sensory functions have raised a lot of confusion in clinical practice. The question of what accounts for these contradictory phenomena has intrigued and preoccupied philosophers, psychiatrists and neurologists throughout history.

\subsection{Explanatory constructs}

To describe the cognitive and emotional shifts observed with CD patients, we focus here on dissociative explanations. The basic assumption of dissociation theory is that under the influence of psychological stress, dissociation can occur between higher level explicit information processing and lower level implicit information processing, in which the explicit information processes fail (Janet, 1907). According to this theory, the apparent contradictions in symptom presentation in the previously mentioned example of conversion blindness where the patient 
rsion blindness could modify sponse to visual information Yet they remain oblivious theim et al. (1979) proposed blind patients performed visual task depending on risual task was presented as a In a clinical setting, we - who claimed to have no his immediate environment, ionably able to maneuver ation room without bumpre. In the case of conversion on patient is unable to move of the body intentionally. led or intentional circumng sleep (Lauerma, 1993) or al., 1998) the patient may, me movement with the al. (1998) clearly demonenon by testing the involun- an affected leg when the contralateral (normal ainst resistance. Compared Is and patients with neuropatients with conversion nificantly more involuntary nb contractions with the se discrepancies between and implicit (involuntary) iory functions have raised a clinical practice. The quests for these contradictory trigued and preoccupied iatrists and neurologists

\section{tory constructs}

itive and emotional shifts ratients, we focus here on ons. The basic assumption is that under the influence ss, dissociation can occur explicit information proevel implicit information the explicit information 1907). According to this ontradictions in symptom eviously mentioned examndness where the patient was able to move around the furniture adequately may be explained by the assumption that, whereas explicit conscious visual information processing fails, the visual stimuli are still being processed on a lower, implicit level (Kihlstrom, 1992). Dissociation theory of CD dates back to Janet (1859-1947), who attributed this functional dissociation of higher and lower level information processing to an attentional narrowing in response to stress, and regarded it as a form of hypnosis. Janet (1925) argued that there is a relationship between childhood traumatization and dissociative symptoms that is mediated by a process in which the traumatized individual uses his or her innate hypnotic capacities to induce self-hypnosis as a defensive response to overwhelming traumatic events (Bliss, 1984; Putnam, 1989).

In line with Janet, contemporary researchers such as Hilgard (1977), Bliss (1984), Nehmia (1991), Kihlstrom (1992) and Oakley (1999a,b) have also argued that conversion symptoms may result from spontaneous self-hypnosis involving a dissociation of sensory or motor functions. Kihlstrom (1992) made an explicit modification of Janet's dissociation model. Although both theories share many features, in contrast to Janet, Kihlstrom regards dissociation as a nonpathological 'normal' psychological process. In his model, the term dissociation is used descriptively rather than mechanistically, and traumatic experiences are no longer incorporated as a causal factor in the development of dissociative symptoms. The most important assumptions and empirical evidence of modern dissociation models, such as Kihlstrom's model, are outlined below.

Several neurophysiological and neuropsychological studies support the view that higher level motor and sensory control functions are disturbed in CD while lower level control functions remain intact. For example, two event-related potential (ERP) single case studies showed intact early sensory processing accompanied by an altered P300 (potential associated with awareness) in conversion patients with motor (Lorenz et al., 1998) and sensory (Fukuda et al., 1996) symptoms, respectively. Also, a single case positron emission tomography (PET) study by Marshall et al. (1997) showed that when a patient with unilateral conversion paralysis of the left leg attempted to move her affected leg, there was no activation of the right primary motor cortex (M1), but there was increased activation in two prefrontal inhibitory structures, the right anterior cingulate (ACC) and orbitofrontal cortex (OFC). The authors concluded that the ACC and the OFC inhibited the prefrontal (willed) effects on the right $\mathrm{M} 1$ when the patient deliberately attempted to move her affected left leg.

Similar brain structures were involved in a case of sensory conversion symptoms (Tiihonen et al., 1995). Also recent motor imagery and motor priming studies (Roelofs et al., 2001, 2002c, 2003,2006; De Lange et al., 2007) showed conversion paralysis to be associated with impaired higher level motor control and relatively intact lower level motor control. In short, there is good evidence from recent neurophysiological and neuropsychological studies that CD is concomitant with dissociated higher level and lower level control processes.

Like Janet, contemporary authors such as Kihlstrom (1992) and Oakley $(1999 a, b)$ note the similarity of CD symptoms and the dissociative aspects of hypnosis. Recent neuroimaging studies provide some support for the suggested overlap between hypnotically suggested phenomena and conversion symptoms. A single case PET study showed hypnotically suggested paralysis (Halligan et al., 2000) to involve the same frontal inhibitory structures (OFC and ACC) as those identified in the above-mentioned case of conversion paralysis (Marshall et al., 1997). Also, using mental hand rotation tasks, Roelofs et al. $(2002 d)$ found hypnotic paralysis to result in impairments similar to those previously observed in patients with conversion paralysis (Roelofs et al., 2001). Moreover, the parallel between conversion symptoms and hypnotic phenomena is supported by the fact that many conversion symptoms have a hypnotic counterpart, and CD is often accompanied by elevated levels of hypnotic suggestibility (Janet, 1907; Ludwig, 1972; Bendefeldt et al., 1976; Bliss, 1984; Roelofs et al., 2002b). The fact that there are many similarities between the symptoms of $\mathrm{CD}$ and hypnotic phenomena has long been recognized in clinical practice. The shared characteristics are a lack of concern regarding the symptoms, a feeling of involuntariness, the influence of motivation and social factors, as well as the display of implicit processing. 
Oakley (1999a) states that several characteristics underlying conversion symptoms and hypnotic phenomena are similar and clearly related to the difference between implicit versus explicit perception (i.e. awareness) or knowledge (i.e. con-sciousness). In his model of self-awareness and consciousness, Oakley distinguishes a higher level self-awareness system and a lower level semi-autonomic executive control system (see also Norman and Shallice, 1986). Oakley contends that most of our actions and thoughts are processed within the lower level executive control system, without subjective awareness. This executive system can be directly influenced by both internal factors (i.e. self-suggestion, conflict, motivation ) and external factors (i.e. heterosuggestion, social or psychological pressure, expectations) and can in turn produce both hypnotic and conversion symptoms. This explains the CD patient's la belle indifference and dearth of explicit knowledge: patients have implicit knowledge of how to move their legs but have no explicit knowledge of this skill, which also explains why they are so unusually indifferent to their plight.

In his model, Oakley regards motor conversion symptoms as the result of the inhibition of wilful movement by the central executive structure. More recently, Brown (2004) has developed a more integrated cognitive model putting more emphasis on the development and content of symptom-related mental representations that are selected by the central executive control mechanisms. Following the cognitive-behavioral tradition, Brown describes putative precipitative (antecedents), moderating (maintaining) and consequential (reinforcing) factors in CD and SD. In the model, autosuggestions or heterosuggestions form only one of the possible precipitating factors that may form the basis for symptom-related cognitive representations. Other factors are sensorimotor experiences associated with physical illness and traumatic events, indirect exposure to physical states in others and socio-cultural transmission of information about health and illness. As far as moderating factors in Brown's model, attentional processes such as the recurrent reallocation of attention onto symptoms by the central executive control system is the primary pathogenic factor in the development of symptom chronicity.
An important example is self-focused attention that may lead to increased awareness of bodily sensations and enhanced reports of bodily symptoms. Other examples of moderating factors are illness worry or behavioral responses such as seeking reassurance.

To summarize, dissociation theory has recently been placed in a broader cognitive-behavioral perspective within current hierarchical cognitive theories (Oakley, 1999a,b; Brown, 2004). Although Oakley regards CD primarily as an autosuggestive disorder, Brown recognizes more factors that may affect conversion and somatization symptoms. It should also be noted that patients with $C D$ do not show the expected elevated scores on measures of dissociation such as the Dissociative Experiences Scale (DES; Bernstein and Putnam, 1986; Roelofs et al., 2001). Authors such as Oakley $(1999 a, b)$ and Brown (2004) propose that the construct dissociation is not necessary require a meaningful link between conversion symptoms and hypnotic phenomena. Despite these drawbacks of dissociation theory, the view that $\mathrm{CD}$ is characterized by dissociation between lower level and higher level control processes is widely accepted and supported by extensive empirical evidence.

\subsection{Clinical applications}

Given the many parallels between hypnotic and conversion phenomena, hypnosis may provide a fruitful context for the treatment of CD.

\subsubsection{A review of the research literature}

The use of hypnosis as a form of treatment for $\mathrm{CD}$ has been extensively described in numerous single case studies and some case series (Janet, 1907; Wilkins and Field, 1968; Kroger and Fezler, 1976; Spiegel and Spiegel, 1978; Sackheim et al., 1979; Patterson, 1980; Conrad, 1985). Oakley (2001) reviewed 12 single case studies, mostly speech disturbances and motor symptoms, in which hypnotic procedures were successfully used in the treatment of CD. Interestingly, as well as employing hypnotic procedures, most studies used a number of adjunctive techniques and strategies such as cognitive-behavioral techniques, speech therapy 
-focused attention wareness of bodily reports of bodily $s$ of moderating havioral responses

theory has recently gnitive-behavioral ierarchical cogni,b; Brown, 2004). primarily as an n recognizes more ion and somatizalso be noted that now the expected $s$ of dissociation iences Scale (DES; coelofs et al., 2001). $99 a, b)$ and Brown truct dissociation meaningful link ms and hypnotic awbacks of disso$\mathrm{D}$ is characterized $r$ level and higher lely accepted and cal evidence.

\section{cations}

reen hypnotic and losis may provide nent of CD.

\section{'esearch}

1 of treatment for ibed in numerous case series (Janet, 68; Kroger and 1, 1978; Sackheim Conrad, 1985). igle case studies, nd motor symprocedures were atment of CD. loying hypnotic ¿d a number of rategies such as s, speech therapy and face-saving strategies. Indeed, most professional hypnosis societies consider hypnosis as an adjunctive technique to be used in support of a broad-based treatment approaches, such as cognitive-behavioral, psychodynamic and rehabilitation therapies.

Many authors recommend a comprehensive, eclectic or multimodal treatment approach. In line with this idea, Wade (2001) used qualitative criteria to evaluate the therapy effectiveness of a selection of multiple case studies of CD patients as well as a broader field of patients with Somatization Disorder (SD), and concluded that a multidisciplinary rehabilitation approach with several simultaneous interventions may be most successful. This conclusion is in agreement with current forms of cognitive theories like the earlier mentioned hierarchical cognitive theory of Oakley (1999b) and the integrative conceptual model of unexplained illness based on cognitive psychological principles by Brown (2004). Brown argues that the treatment of choice depends on a detailed assessment of the patient's symptoms, the factors associated with their onset and maintenance. He goes on to say that it can involve cognitive-behavioral therapy, suggestive therapy with or without hypnosis, psychodynamic ally-oriented therapy, and occupational therapy or physiotherapy.

Two studies by Hoogduin and Van Dyck (1992) and Moene et al. (1998) used such forms of eclectic therapy. In the study by Hoogduin and Van Dyck, eight inpatients with CD received hypnosis-based treatment and physical revalidation. At follow-up (6-72 months post-treatment), three patients had completely recovered and five had improved considerably (with one of the five showing a short relapse). In Moene $t$ al. (1998) the authors describe a pilot study consisting of eight consecutive CD patients. All patients had been diagnosed with $\mathrm{CD}$ for many years. The mean duration of treatment for this clinical trial was 2 months as an inpatient and 20 sessions as an outpatient. One patient dropped out and seven completed treatment with symptom removal. Three patients relapsed during follow-up.

Controlled studies on the treatment of CD are scarce and, until recently, there were none available controlling for natural changes that may occur without intervention. Controlled single case studies have shown cognitive-behavioral, operant, cue conditioning and symptomfocused approaches to be promising (Agras et al., 1969; Hersen et al., 1972; Ohno et al., 1974; Kallman et al., 1975; Turner and Hersen, 1975). However, controlled clinical trials providing information on the successful treatment of long-standing CDs and follow-up information are very few in number (Munford and Paz, 1978; Montgomery and Espie, 1986; Kop et al., 1992). To our knowledge there are only two randomized controlled group studies on the treatment of CD and SD. They followed an eclectic approach including hypnotic techniques involving both inpatients (Moene et al., 2002) and outpatients with CD (Moene et al., 2003b).

In the Moene et al. (2002) study, the investigators treated 45 adult inpatients with CD of the motor type, or SD with motor conversion symptoms, using a comprehensive 2-month treatment program. All patients participated in group therapy aimed at increasing the patients' problemsolving capacity using behavioral and cognitive techniques. In addition to the group therapy, the patients followed an individual symptomdirected program consisting of physiotherapy, individual exercise sessions and bed rest. A total of 24 patients received additional hypnotic treatment with 8 weekly l-h sessions using symptomoriented and exploratory techniques. The control group of 21 patients received an additional treatment without specific interventions for conversion symptoms. For patients who completed follow-up, the mean time as an inpatient was 2.9 months. For the total sample, significant treatment results were found on all outcomes measuring symptom reduction and reduction of impairments in the domains of physical activities, activities of daily life and social activities. At a 6-month follow-up, the improvement was maintained and even increased across all outcome measures. Use of hypnosis appeared to yield no additional benefit.

The second randomized controlled clinical trial involved 44 outpatients. Moene et al. (2003b) found that patients with conversion symptoms who had completed a 10-week hypnosis-based therapy protocol (symptom-oriented and exploratory techniques) significantly improved relative to baseline. Their improvement exceeded 
that of a wait-list condition and was maintained at 6 -month follow-up. Twelve patients were referred for further treatment sessions beyond the 10 -week post-treatment assessment with a mean number of 6.3 extra sessions.

The findings from these trials suggest that hypnosis-based interventions are efficacious for patients with conversion symptoms. Nevertheless, the hypnotic techniques appeared not to add significantly to the efficacy of the eclectic, inpatient treatment program. Also, in both studies hypnotizability was not found to contribute specifically to treatment outcome. However, the effect sizes of the hypnotizability/outcome correlation ranged from 0.25 to 0.35 . This is a typical effect size for the association between patient variables and psychotherapy outcome (Garfield, 1994).

In the case presentation section of this chapter, the eclectic approach used by Moene et al. $(2002,2003 b)$ will be described and illustrated in more detail. The various hypnotic techniques that are used in this approach are described immediately below.

\subsubsection{Hypnotic techniques in CD}

There are no studies specifically examining the effectiveness of various hypnotic strategies or techniques for the treatment of specific CD symptom categories such as paralysis or aphonia. Nevertheless, the literature describes two kinds of hypnotic procedures: symptom-focused and exploratory techniques. The symptom-focused strategies involve the aforementioned predominantly cognitive-behavioral, symptom-oriented approaches, as well as the direct and indirect influencing of symptoms by operant conditioning techniques and cue conditioning. In these strategies, hypnosis is used formally or in a hypnotic context.

Exploratory techniques such as revivification or age regression refer to insight-oriented and expression-oriented psychotherapeutic techniques. They are used to explore emotions that are associated with the symptoms or their onset. It is suggested to the patient that giving expression to the pent-up or dissociated emotions and dealing with them both during hypnosis and in the waking state may positively influence the symptoms. In both the symptom-oriented and exploratory hyprotic approaches, direct, indirect and post-hypnotic suggestions of symptom reduction are used. Some authors stress the importance of learning self-hypnosis. Indeed there is some evidence that home practice of hypnotic relaxation may be a therapeutically significant aspect of symptom reduction strategies (Spinhoven, 1989).

\subsection{Symptom-oriented techniques}

In this section several symptom-oriented techniques will be described and illustrated for the main symptom complexes: motor, sensory and pseudo-seizures or convulsions (pseudo-epilepsy; PES), followed by a general description of explorative techniques.

\subsubsection{Motor symptoms such as paralysis, contractures and uncontrollable movements}

26.5.1.1. Making use of the present rest capacity with flaccid paralysis

In cases of paralysis, suggestions are for the patient to pay attention to any kinetic reactions he/she may be having in the affected limb (e.g. tingling, pain, and differences in temperature or tiny muscular spasms in the affected limb. These sensations can be strengthened by suggestive reinforcement such as 'the longer you concentrate on the tiny muscle spasms, the stronger they will become'. As sensations begin to strengthen, we move to suggestions for small muscle movements followed by larger muscle movements. Emphasizing and praising every occurrence of little (spontaneous) movements is important.

\subsubsection{The nonaffected limb helps} the affected one

In this intervention (Hoogduin et al., 1993) the patient is asked to concentrate on the nonaffected limb, to become aware of the sensations that are present in the limb, to name them and to visualize them. The therapist then gives the suggestion that the affected body part has forgotten or unlearned how to feel the sensory perception and physical sensation, and that the nonaffected limb is going to re-train the affected one. Thereafter, suggestions follow that certain 
zstions of symptom .e authors stress the self-hypnosis. Indeed at home practice of be a therapeutically tom reduction strate-

\section{Jriented}

nptom-oriented techand illustrated for the zs: motor, sensory and sions (pseudo-epilepsy; eneral description of

\section{toms such as res and ements}

of the present rest aralysis

uggestions are for the to any kinetic reactions the affected limb (e.g. ences in temperature or the affected limb. These ngthened by suggestive the longer you concenspasms, the stronger they ons begin to strengthen, for small muscle moveger muscle movements. ing every occurrence of rements is important.

ected limb helps

oogduin et al., 1993) the acentrate on the nonataware of the sensations limb, to name them and therapist then gives the ected body part has for${ }_{N}$ to feel the sensory persensation, and that the ng to re-train the affected tions follow that certain movements and motor sensations can flow from the healthy area to the affected body part so that the patient can also experience it there. (For an illustration, see Section 26.9, case 1.)

\subsubsection{Relaxation and imagination}

Also for symptoms of hand contraction, hypnotic suggestion can be used to influence the symptoms and enlarge subjective feelings of control. The hypnotic suggestion involves relaxation of the arm and hand muscles together with presentation of the image of a balloon being blown up in order to get the hand with the contracted fist to open and close by itself (Hoogduin et al., 1993).

26.5.1.4. Imagination of normal functioning in the past

With this technique, while under hypnosis the patient goes back to the time when voluntary movement still functioned. Moene and Rümke (2004) used this technique with a young woman who had paralysis of a hand.

Illustration: After hypnotic induction, Joan went back to thoughts of a lakeshore at the campgrounds where she always feit very happy. Then the suggestion was given for her affected hand to pick up stones and let them slide away. Along with this, the suggestion that she also experience this with increasingly more sensory perception was given, and aiso that she should feel the precise tension in her hand muscles that was necessary to pick up the stones. After this, other different images were used, such as feeling the sand in her hand and making sand drawings with her hand in combination with suggestions of increasing muscle strength, sensory feeling and recovery of movement.

A comparable approach for patients with aphonia is from Drost (1996), who used this technique diagnostically and therapeutically in an informal hypnotic context to demonstrate the functional character of speech disturbances by letting patients go back to a pleasant experience in time when speech was still normal. During hypnosis, the therapist suggests that the patient begin talking about the pleasant situation whereby the voice can 'relearn' the skills to talk again.

\subsubsection{Making use of the fact that} during sleep, the symptoms are absent

This technique is mostly applied for tremors or pseudo-ataxia. Here the clinician makes use of the fact that many CD symptoms abate during sleep (Hoogduin and Van Dyck, 1990). The treatment is built up step-by-step. First, while in hypnosis, the patient is asked to lie down in a sleeping position and to try to sleep. Next the therapist gives suggestions for rest and muscle relaxation. Finally, the explanation is given to the patient, who is in a state of deep relaxation, to imagine that he has reached the mental state that is comparable with the sleep whereby the symptoms will abate. Eventually the same sequence is followed but with the patient in an upright (i.e. sitting) position. The following sessions might include suggestions that the patient falls asleep with open eyes, while remaining relaxed. The patient is taught how to do self-hypnosis and instructed to practice the exercises at home.

\subsubsection{Catalepsy induction}

This technique (developed by Sacerdote, 1970, and termed reverse hand levitation), can be used when the patient has no control over his or her muscular movements or in the presence of tremors or pseudo-ataxia (Erickson, 1980; Hoogduin and Van Dyck, 1990).

The method is as follows: the patient sits in a chair with elbows supported on the armrests. The therapist takes the wrist between thumb and index finger and lifts the lower arm to a vertical position. By now changing the support of the arm and letting it loose again, gradually a situation of catalepsy, or a transformable stiffness or wax-like malleability is suggested and sustained by the CD patient. The catalepsy can again be applied in different extremities or in the torso in the same manner. A complete body catalepsy is stimulated for patients who have trouble with uncontrollable movements in their whole body. The patient first practices with catalepsy of a limb and, when that is successful, the suggestion is given that this experience (the feeling and the actual perception of stiffness) can generalize through the whole body. Another method is to make the opposite movement alternately with the body until it feels frozen or stiff (for an illustration, see Section 26.10, case 2).

In a number of cases there is a so-called rebound effect, a temporary return of the tremors or uncontrollable movements after the catalepsy has subsided. It would be prudent to anticipate 
this phenomenon in the treatment so that a patient does not become anxious or disheartened when it occurs. Experience has taught that with longer duration of control over the movements, the rebound effect gradually diminishes. In order to influence this, one can use posthypnotic suggestion to support the notion that the relief from tremor will remain increasingly longer.

\subsubsection{Letting go}

Another applicable method for shaking and tremors is letting go. Many patients try to resist the uncontrollable movements by tensing their muscles. The effect of this strategy is often more movement, not less. In many cases, explanation of this unwilled effect, in combination with the prescribed rest periods and letting go of the resistance, can be the solution to the problem. Progressive relaxation with or without hypnosis can enable the patient to let go of the resistance and thus gain an element of control. During hypnotic relaxation, the patient can be given the suggestion not to resist the movements, to shake them off, and to make the body heavy and languid, whereby the movements will become increasingly slower and eventually shall stop.

In complicated situations, cue conditioning for distraction of the attention can be a supportive technique. It is sometimes almost impossible for patients who shake to direct attention on their exercises or to breath normally.

Illustration: Mr van Zuid has a shaking leg. While administering a local stimulus on his arm for approximately $15 \mathrm{~s}$, he receives the instruction to focus his attention fully on the area where the stimulus is given and to combine this with deep stomach breathing, whereby he utters the word 'loose' while exhaling. The letter ' $s$ ' from the word is pronounced until the end of the exhalation: stimulus inhaling exhaling loossse... The next stimulus is only given when the shaking increases again.

\subsubsection{Somatosensory symptoms (e.g. anesthesia, tunnel vision or blindness and deafness)}

Sensory disorders often accompany CD, but seldom endure. With recovery from the disorder, recovery of sensations usually occurs.
The therapist can offer this suggestion as support or the suggestion that sensations are the beginning of recovery from the symptoms. The assertive re-appearance of total loss, or the change in function of sight or hearing during certain periods of time is less prevalent than with motor conversion symptoms.

\subsubsection{Making use of visual and auditory imagination in conversion blindness or deafness}

In order to support the patient's motivation, it is important that the therapist starts with pleasant and familiar images, sounds or objects. The patient receives the suggestion to call upon these while going into a deeply relaxing state during certain times of the day. Thereafter, the suggestion is given that 'it is precisely from this positive and relaxed state of mind, that consciously learning to see and hear will be facilitated, and that one day it will manifest itself, initially just a bit, but after that, there will be more and more conscious awareness of images or sounds during longer periods of time'. De Haan and Bergsma (2002) describe the use of rest capacity in the treatment of a young woman with conversion blindness. She initially learns to visualize. After inducing hypnosis, she has to stare at an object in the therapy room, and then to visualize it with her eyes closed. When this is achieved, she receives the task of staring at objects for certain periods during the hours that she is not blind at home, and then to visualize them while hypnotized during the hours of the day that she is blind. Furthermore, she receives the suggestion that she must wait until her eyes are at the point when she no longer precisely knows if she is visualizing or actually seeing the object. In our experience, when a patient begins to voice this type of confusion, restoration of function is close at hand.

fllustration: Paul, age 19, has a partial loss of vision. He sees differences in color, but nothing more. This improves at certain times of the day, and he is somewhat able to perceive, albeit vaguely, what his surroundings look like. The therapist uses this for treating the complaints. The patient receives visualization exercises with the task of playing with the colors, to intensify and minimize them, as well as making the color areas larger and smaller. He must 
this suggestion as that sensations are from the symptoms. e of total loss, or the at or hearing during less prevalent than iptoms.

visual and onversion

ient's motivation, it is st starts with pleasant nds or objects. The ion to call upon these relaxing state during hereafter, the suggessely from this positive hat consciously learnfacilitated, and that elf, initially just a bit, more and more cones or sounds during e Haan and Bergsma f rest capacity in the man with conversion ms to visualize. After s to stare at an object then to visualize it this is achieved, she at objects for certain hat she is not blind at se them while hypnof the day that she is ceives the suggestion $r$ eyes are at the point isely knows if she is ng the object. In our $t$ begins to voice this oration of function

$s$ a partial loss of vision. but nothing more. This of the day, and he is albeit vaguely, what his e therapist uses this for a patient receives visualask of playing with the nimize them, as well as er and smaller. He must perform this exercise daily and register the results. Even though he faithfully practices, he doesn't really progress. There is approxinately a 30 per cent improvement. Psychologically, things continue to improve for him. The conditions for recovery surely appear to be present through this. Before release, he goes to see his ophthalmologist who reports that his condition is satisfyingly inproving, and prescribes vitamin $B$. The therapist realizes that Paul wants to relinquish his symptoms without loss of face. She gives Paul the powerful suggestion that the complaints will completely disappear because things are going so well right now. She also mentions that the ophthalmologist sees the situation positively. Three months later when sitting in the waiting room, Paul sees the therapist and says that she really looks exactly as he had imagined she would. His vision seems to have completely returned.

\subsubsection{Seizures or convulsions}

\subsubsection{Hypnotic self-control procedures}

Kuyk et al. (1999) used hypnosis for the identification of PES and showed that hypnotic recovery of memory of the events occurring during a seizure was only possible in the case of pseudo-seizures and not in real seizures. This technique is called hypnotic recall and it can also be used therapeutically to explore the mental state of the patient during a pseudo-seizure. It may also help to enhance control over symptom-eliciting stimuli and the pseudo-epileptic attacks themselves. The patient is told that such attacks are the result of increasing tension in the body from long-lasting strain, acute stress or threat without there being an electrical release in the brain. The release of tension takes place in the muscles. Usually with this, one shifts into another state of consciousness. Then it is explained that hypnosis is a state of mind wherein one can enter into this changed state of consciousness, before as well as during the attack (Moene, 1991; Moene et al., 2003a). The patient is administered a hypnotic procedure and is asked to think back about the beginning of the last attack. Evocation of this experience is done as vividly as possible by asking about (and intensifying) the sensory as well as the emotional experiences. When it is clear which tension-eliciting situations or experiences the patient reacts to, other attacks can also be charted in this way.
Through this, the patient and the therapist get an image of situational triggers that immediately precede the attacks. The patient can decrease the burgeoning tension and can learn to resist the attacks by practicing with antagonistic reactions during hypnosis and in a waking state. An example of such a method is cue conditioning.

Illustration: Mrs James and cue conditioning. A tingling sensation is the first warning that an attack is underway. In hypnosis, Mrs James learns to relax quickly. When she feels the tingling sensation, she stops doing whatever she is doing, she goes into a quick trance by thinking of her relax-chair which is a synonym for deep relaxation and rest; she then takes a deep breath, holds it for a few seconds, breathes out and lets all tension leave her body.

\subsubsection{Provoking attacks: prescribing the} symptom as a self-control procedure

This approach is indicated in cases where the occurrences of attacks are strongly determined by anticipatory anxiety (Hoogduin et al., 1996). The relationship between anxiety and the attack is explained to the patient. During hypnosis, the patient is given suggestions vividly to re-live one of the more recently occurring attacks and to describe the antecedent situation. Then, still during hypnosis, an attack is induced by deliberately using these situational triggers with attendant anxiety. As the symptoms eventually recede, the therapist emphasizes that if the patient can 'turn on' the attacks by becoming anxious, he/she can learn to control them by becoming relaxed in the face of the situational triggers. As this process of elicitation and recovery is repeated, the patient learns how to elicit and terminate the attack. The final goal is that the patient learns to avoid attacks by becoming more conscious of the antecedent events and/or by interrupting the anxiety before it escalates.

Illustration: During hypnosis, John King, a 36-yearold man, goes back in time to the moments before the last attack. The therapist asks him to concentrate on the first signals, and he intensifies them by repeating them. The attack then begins, and the therapist describes what happens: 'I see your arms spasm, your breathing speeds up, you now begin to shake your legs too. It's going well, and now we're going to help you get out of the attack. You will first notice that your breathing will calm down and your 
arms will feel heavier. This is the first sign that your body will feel more relaxed, calmer and heavier?

Every change in the appearance of John's situation is noted and is coupled to the suggestions that the relaxation will increase and that this is a sign that he is returning to normal consciousness. The exercise is discussed after hypnosis is terminated. The patient is complimented for his boidness and accomplishment.

Then a brief form of exercise program is discussed and practiced with him. The core of this program is that the patient goes increasingly deeper into hypnosis and purposefully imagines the cues that precede an attack. Then, with self-suggestions of relaxation, heaviness, and calm breathing he counter-conditions the cues.

\subsection{Expressive techniques}

Expressive techniques, focused on the emotional experiencing of trauma or conflict, may be helpful in achieving clinical improvement. However, they should be applied with great care and should never be focused on the literal recovery of lost memories given the danger for iatrogenic suggestion during therapy (Brewin, 2003; $\mathrm{McNa}$ ly, 2003). If expressive techniques are used with trauma patients, this has to be integrated in a therapeutic context in which traumarelated problems are carefully treated. This may be particularly important for patients with pseudo-epileptic attacks, because several authors emphasize the role of sexual abuse in the etiology of PES (Betts and Boden, 1992; Bowman, 1993; Bowman and Markand, 1995).

\subsubsection{Revivification and/or age regression}

These techniques can be used in cases where the symptom onset is associated with a specific distressing experience. The patient returns to thoughts of pertinent occurrences or to the initial period of the CD whereby the suggestion is given that the ability to express the emotional experiences of the past will positively influence the symptoms.

Illustration: Mary, a 4l-year-old woman, has had total paralysis and numbness in her right leg for 4 years. She is aware of her incest history, confirmed through a third party. Symptom-oriented techniques are not successful in restoring movement to her leg, possibly because of the absence of any sensations. Use of an exploratory technique is then considered. Mary has reported a traumatic experience wherein the offender abused her such that he so forcefully pushed her right leg against the wall that, after initially feeling much pain, she then experienced her leg as completely numb and nonexistent. During a hypnosis session, she recounts this experience, which makes her anxious. The therapist reassures her and offers a plausible rationale that he therapeutically uses, namely that her leg surely was there and still belongs there, but that she didn't feel her leg because it was repressed for a long time. Further, she is asked what she would have preferred to do with that leg. When she reveals that she would have wanted to kick the offender away, the therapist decides to use this wish in order to awaken the paralyzed leg with its first movement. Mary receives the suggestion to make a strong kick with the nonparalyzed leg and to allow the symbolic expression of resistance flow to the paralyzed leg through which it too will be able to move again. Contractions of smail and large muscles in the affected leg are then observed.

Brady and Lind (1987) describe an example of a similar technique in a case of hysterical blindness. A young man is blinded after a fire in the house where he grew up, where his sister was seriously wounded. During the hypnosis, he reveals that he blames himself for first thinking of himself and escaping from the house, going back later to rescue his sister who had already been rescued by the fire department. After this is clarified, the suggestion is given that this inner conflict should be discussed in psychotherapy and his vision can recover.

\subsection{Complications arising during treatment with hypnosis}

It is important that therapists are aware of the fact that during all phases of the hypnotherapeutic treatment for $\mathrm{CD}$, unexpected phenomena and patient responses can arise. Usually these reactions are described as idiosyncratic responses to hypnotic suggestions (e.g. the raising of both arms when suggestions for unilateral arm levitation is given). For clinical practice the 
g movement to her ssence of any sensa$r$ technique is then I a traumatic experiJused her such that ight leg against the ng much pain, she ; completely numb ypnosis session, she I makes her anxious. ıd offers a plausible ically uses, namely e and still belongs 1 her leg because it ne. Further, she is referred to do with nat she would have away, the therapist rder to awaken the sment. Mary receives rong kick with the llow the symbolic $\checkmark$ to the paralyzed ll be able to move and large muscles erved.

ribe an example of if hysterical blindafter a fire in the lere his sister was the hypnosis, he f for first thinking I the house, going - who had already tment. After this is en that this inner in psychotherapy

\section{; arising ith hypnosis}

$s$ are aware of the "the hypnotheraxpected phenoman arise. Usually 1 as idiosyncratic uns (e.g. the raising ons for unilateral inical practice the fact that these effects sometimes occur must be accepted. It must be understood, however, that when 'something odd' happens, it can often be woven into the intervention so as to support the therapeutic work. Moene and Hoogduin (1999) offer detailed guidelines as to how to accommodate these phenomena and utilize them in a positive and creative way. They describe a patient who has a generalized reaction to hand levitation. Their main message to the patient is that what appears to be an initial worsening or transformation of symptoms with hypnosis is really an opportunity for the patient to enhance control over the presentation of syniptoms and improve the understanding of them.

Illustration: Mrs D., with a hypnotizability score of 4 out of 5 [Stanford Hypnotic Clinical Scale (SHCS) Morgan and Hilgard, 1974] is treated for a paresis of the left leg. In the course of the treatment she is given instructions for hand levitation to which she responds positively. 1t is then suggested to her that because her arm has successfully and adequately responded, hypnosis might be the indicated method to learn how better to control body movements. Shortly afterwards the therapist sees her raising both legs spontaneously. The therapist decides to use this unexpected response. She tells Mrs D. that she must be a very talented hypnotic subject to be able to use so quickly what she has just learned, and she indicates that this could well mean that the recovery from the paresis will take place faster than initially expected. After this, the therapist gives Mrs D. suggestions about a further increase of the upward movement. She is then urged to concentrate intensely on the sensations in her paralyzed leg and become aware of these sensations to break through the blockage of sensation in this leg. Following suggestions of heaviness, formal hypnosis is ended. Further hypnotherapeutic sessions focus attention on feeling sensations and muscle contractions in the paralyzed leg.

\subsection{The structure of the case illustrations}

The hypnotic techniques described in the previous sections are seldom employed on their own in the treatment of CD and SD. In our view, a hypnotic intervention acquires its therapeutic impact to the degree that it is embedded in a comprehensive and well-articulated therapeutic frame. Before we describe in detail the hypnotic strategies used with two CD patients, we first set the stage with a brief description of the therapeutic context in which these strategies were used at the psychiatric Hospital De Grote Rivieren in Dordrecht (The Netherlands) (for a fuller description, see Moene et al., 1998); Moene and Rümke, 2004).

\subsubsection{The treatment model: a brief outline}

Given the psychosomatic nature of CD and SD, both the assessment and treatment phases are carried out with the close co-operation of psychotherapists and physiologists. This enables a combination of psychological interventions and physical rehabilitation, which is of particular importance in the case of chronic motor symptoms.

\subsubsection{Assessment phase}

1. Somatic/neurological screening to rule out organic disorder.

2. Behavioral analysis by a psychotherapist: identification of predisposing, precipitating and perpetuating factors that triggered the onset of the symptoms (e.g. history of physical illness, life events); assessing psychiatric co-morbidity and investigation of relevant topics such as the patient's own theories regarding the cause of the symptoms and involvement in insurance or juridical procedures.

3. Examination by a physiotherapist (including EMG assessments) wherein the symptoms and the consequential physical limitations are inventoried. The motor skills and limitations, the physical burden and the necessary help with activities of daily life are charted.

\subsubsection{Consultation}

The patient and his family are offered a plausible rationale to explain the symptoms and the treatment model presented. It is important that the rationale squares with the patient's subjective experiences and his belief system, and that the treatment is received by the patient as logical. 


\subsubsection{Treatment phases}

1. Psychotherapy (individual and/or systemic) focused on the precipitation, the maintenance and the consequential factors of the disorder. Cognitive-behavioral interventions are also directly focused on the symptoms.

2. Hypnosis that is symptom oriented or/and expressive. In order to make successful use of hypnosis, the patient must be hypnotizable, and have the ability to concentrate on sensory as well as the motor experience. Motivation is also required. It is important to explain the use of hypnosis and to discuss any lingering concerns. For this, the earlier mentioned facts about the relationship between hypnosis and CD are used.

3. Individual physiotherapy for training of the lost, reduced or altered physical functions and counteracting the possible secondary physiological consequences of long-standing CD, such as muscular atrophy, pain or poor blood circulation.

4. Group therapy aimed at improving the patient's problem-solving techniques and social skills training to prepare patients for returning to normal social interactions without the symptoms.

\subsection{Case 1. A symptomatic approach using hypnotic imagery and behavioral methods}

Mrs Jones, a 46-year-old married woman with three children ages 21,19 and 15 has conversion paralysis in both legs and the left arm, diagnosed as conversion symptoms in the context of a somatization disorder. She uses an electric wheelchair in order to move around. From her youth on, Mrs Jones experienced multiple physical complaints such as chronic fatigue, loss of muscle strength, difficulty standing and walking, paresis of the left arm, aphonia and double vision, all of which cannot be properly explained by medical examinations. She reports that she had been exposed to physical threats and explosive outbursts of anger from her father for years and that he had sexually abused her once. Third parties confirm this.

Mrs Jones had her first two children soon after getting married She was unhappy because it was necessary for her to work in the family business. Over the years, Mrs Jones consulted many physicians and specialists for her physical complaints. She received many explanations. She says that this made her feel very insecure. When she was 33 years old, her motor problems started. First, there was loss of strength in the left arm, and later paralysis of the same arm and of both legs. She was shocked and relieved to hear a diagnosis of multiple sclerosis during an eye examination. On the other hand, she also had her doubts about the diagnosis because her symptoms did not conform to those of multiple sclerosis patients. Her children and husband prepared themselves for having an invalid mother and wife. They shared the household tasks and received assistance from home help services.

Several antecedent and consequent factors are identified as being relevant for the treatment. As assessed by the SHCS (Morgan and Hilgard, 1974; Oyen and Spinhoven, 1983) Mrs Jones was highly hypnotizable (score of 5 on the SHCS). Further, she appeared physiologically reactive to suggestions regarding her having multiple sclerosis and past abuse by her father (see also Brown, 2004). Other noteworthy factors were her belief that the symptoms were attributable to multiple sclerosis; her fear of being stigmatized if her neighbors knew of her psychiatric treatment; and her family's reinforcing illness behavior.

The assessment team (psychotherapist, physical therapist and, in this case, the neurologist) advised the couple that: (1) the patient does not have multiple sclerosis; and (2) the hospital specializes in the type of disorder that she does have. The patient was then told she has a diagnosis of CD, a disorder that is treatable. The patient was told that if she felt she must tell neighbors something about her treatment she can say 'a dysfunctional muscle disorder was discovered that luckily can be helped with intensive training?

If the patient is convinced that muscles and nerve paths are irrecoverably defective, then mobilizing hope is quite difficult. Hence, the 
used her once.

o children soon inhappy because irk in the family Jones consulted ; for her physical y explanations. el very insecure. motor problems f strength in the of the same arm s shocked and nultiple sclerosis t the other hand, ut the diagnosis not conform to nts. Her children elves for having They shared the assistance from

quent factors are $r$ the treatment. gan and Hilgard, 983) Mrs Jones re of 5 on the I physiologically ling her having abuse by her ther noteworthy the symptoms clerosis; her fear neighbors knew and her family's

herapist, physical he neurologist) patient does not (2) the hospital sorder that she ien told she has that is treatable. felt she must tell her treatment muscle disorder be helped with

hat muscles and defective, then cult. Hence, the physiotherapist and the psychotherapist thoroughly explain the difference between the destruction of muscles and nerves resulting from organic injury and pathology associated with CD. Furthermore, Mrs Jones is told:

People with conversion motor symptoms have forgotten or unlearned the conscious control of body movement, but this procedural knowledge is present at an unconscious level. The fact that patients can no longer consciously execute their movements has to do with a mechanism that is called dissociation. This occurs when people are under a lot of stress for a long period of time, are exhausted or have had drastic or traumatic experiences. Because of this, the conscious and unconscious (automatic) functioning of our movement has split apart. The nervous system is disrupted and the patient loses the conscious control of his voluntary movements. In a way it is a little like a computer. All the hardware can be present and installed in the correct manner, but if there is no well-functioning software, it is useless. The reason we use hypnosis is that for some patients it can help re-connect them with knowledge about movement-knowledge which they have unlearned because of stress. Once this connection is made, a patient can refine their movement pattern with the help of physiotherapy.

The explanation is supported with drawings and schematic representations of the body and of the psychological processes that the patient has experienced. The therapist elaborates with examples from the patient's own history and symptom status. Finally, the therapist mentions that in case stressful or traumatic events are factors that have caused the disruption, they will be examined and dealt with in the treatment.

\subsubsection{The phases of the hypnotic strategy}

The first focus of the treatment with Mrs Jones is the paralysis of the left arm and the utilization of the fact that her right arm is still functioning normally. The hypnotic strategy consists of different phases:

1. Introduction of hypnosis and preliminary exercises.

2. Using the technique where the nonaffected limb teaches the affected limb.
3. Shaping of other movements of the paralyzed hand and arm.

4. Generalization of movements in normal daily life.

5. Imagination of normal functioning in the past with the paralyzed legs.

\subsubsection{Introduction of hypnosis and preliminary exercises}

Mrs Jones learns how to relax her body with a combination of suggestive and relaxing visualizations. To create a positive and hopeful therapeutic climate, during hypnosis Mrs Jones is given the suggestion that she will now learn a new form of control over her body movements, but not by the exertion of her will, because patients with CD know that as they try to move, they cannot exercise this kind of willed and conscious control over their body movements. She is told that there is another kind of control, a more unconscious, automatic control that she will learn to apply skilfully in hypnosis. And when she will be able to move her affected limb in hypnosis, she can generalize this ability to the normal waking state. Then the physiotherapist will give her a training program to help her strengthen her muscles, and learn to co-ordinate her movements so that she will be able to walk and move again. This hypnotic exercise is audiotaped and like all of the following exercises, Mrs Jones is told to practice it herself twice a day, listening to the instructions recorded on the cassette, and register how deeply involved and relaxed she feels when doing the exercise (low, medium or high).

\subsubsection{The nonaffected to affected limb} technique

The therapist uses the normal movement possibilities of the right arm and hand. The hypnotic technique called the nonaffected limb helps the affected one is then used in different variations. At first, arm levitation is induced with the right arm (unaffected arm). Mrs Jones is asked to open her eyes during hypnosis, to look at her arm and amaze herself that she is able to do this. Thereafter, she concentrates on the sensory and motor perceptions that are present in the nonaffected arm. She verbalizes and visualizes them. Then she receives a forceful suggestion that the 
right arm's movement perceptions and the muscle tension will flow through from the healthy arm to the affected left arm, causing it to rise as well. The suggestion is given that she will experience this as she concentrates on the image of the affected arm making the same movement. Furthermore, all the possible physical perceptions in the paralyzed arm are suggested, stimulated and embedded in the framework of revitalizing the nerve and muscle activity. It is important that all of the perceptions that Mrs Jones reports, such as differences in temperature, stinging, tingling and muscle movements, including minuscule ones, are used by the therapist and expanded upon in order to achieve a first movement.

Mrs Jones is successful in lifting her left arm a few centimeters. Now that Mrs. Jones has witnessed the movement, the therapist gives the post-hypnotic suggestion that she can relearn all the other movements that are needed to return the control of the arm to her. After hypnosis is terminated Mrs Jones watches the videorecording of the session and sees for herself what she has achieved. Just as with all of the following steps, she is vigorously praised. Mrs Jones then shares the video with her family. In the next sessions the therapist suggests both raising the arm (suggestions that it is becoming lighter) and lowering the arm (suggestions that it is getting heavier.

\subsubsection{Shaping of other movements of the hand and arm}

Now Mrs Jones learns to make a fist and then to relax it. For this she must place her two hands next to each other on her wheelchair tray. During hypnosis, the therapist asks her to make a fist with her healthy hand, to concentrate on the perceptions of her hand and the muscle tension that is needed to make the fist. Then she is given suggestions comparable with the first exercise about the flowing through of movement-related perception to the paralyzed arm. She succeeds in making a fist with her paralyzed hand after practicing a few times and with encouragement from the therapist. Over a number of sessions other movements are similarly supported in the following order: moving the arms sideways, like directing an orchestra; folding her hands like as in prayer; moving her fingers by imagining that she is playing a piano; and finally more routine daily movements. The movements are in the order of difficulty.

\subsubsection{Further movements throughout} the week

When Mrs Jones masters the movements in hypnosis, she is given the post-hypnotic suggestion that: 'You come out of trance after practicing, but the arm will stay in trance for a longer time so that the movements can be retained during 'normal' consciousness ... every time more and more easily and longer ... and that gradually only looking at the arm and imagining that it is functioning normally is sufficient to allow it to occur ... and finally the movements will feel just as normal as those of the healthy arm ...

\subsubsection{Imagination of normal functioning} in the past with the paralyzed legs

The second phase of the treatment focused on the paralysis of both legs. In this case it is difficult to use the same method as with the paralysis of the left arm, because both legs are paralyzed. First the patient must literally witness her muscles generating movement. Therefore, the physiotherapist uses a form of electro-technical application, an EMG (electromyogram) by which Mrs Jones' muscle contractions are awakened. The physiotherapist applies a local, mild and harmless electrical stimulus whereby muscle contractions are induced in one of the paralyzed legs. When the patient experiences the muscle contractions and sees them translated in an intensity graph on the display of the EMG apparatus, she is convinced that her muscles and nerve paths function well enough for her to regain control of them. It is also possible to evoke muscle contractions manually. When the physiotherapist varies the speed by which he moves the paralyzed leg of the patient, reflexive movements can be realized.

When she succeeds in independently waking the contractions, the exercises are geared towards strengthening them. Thereafter, she practices daily with tensioning, and the amount of times that she succeeds in tensing the muscle group is recorded in a graph.

Hypnosis is now used as an adjunct to the physiotherapeutic treatment. Mrs Jones is told that she can use her knowledge of her previous 
daily movements. The der of difficulty.

ements throughout

the movements in hypst-hypnotic suggestion ince after practicing, but ice for a longer time so be retained during 'norevery time more and ... and that gradually and imagining that it is s sufficient to allow it he movements will feel f the healthy arm ...

of normal functioning ralyzed legs

the treatment focused $h$ legs. In this case it is ne method as with the $\mathrm{rm}$, because both legs patient must literally generating movement. herapist uses a form application, an EMG hich Mrs Jones' muscle ed. The physiotherapist and harmless electrical iscle contractions are - paralyzed legs. When the muscle contractions $d$ in an intensity graph EMG apparatus, she is uscles and nerve paths rr her to regain control ssible to evoke muscle When the physiotheraby which he moves the patient, reflexive red.

I independently waking exercises are geared them. Thereafter, she ioning, and the amount ds in tensing the muscle raph.

$d$ as an adjunct to the ment. Mrs Jones is told owledge of her previous experiences with hypnosis to 'get into contact with her legs' and try to let all the physical sensations she knows from her arms now flow to her legs. Furthermore, it is suggested that she can help the therapeutic process when she imagines her legs moving. The therapist uses the age regression technique to go back to a time when normal movement in her legs was still possible. Then she has to choose a pleasant experience from the past in which she was standing and walking. The suggestion is given that:

when you see yourself doing so, you can come closer and closer to yourself like a camera zooming in .... and become more and more aware ... of the feelings and sensations the movements give you ... and then, at a certain moment ... you yourself will be the one who is experiencing the standing and walking.

These exercises go well, but then a complication arises. There is stagnation in the physical rehabilitation program. It appears that Mrs Jones trains too intensively because she is afraid her family might think that she is not working hard enough in her therapy and that she will not be allowed to return home, but instead has to go to a rehabilitation clinic. This causes a great deal of anxiety which in turn compromises therapeutic progress. This is discussed with her to highlight the relation that exists between tension-provoking events and the worsening of her symptoms. After a family session with psychotherapist and physiotherapist in which this is discussed, Mrs Jones is reassured and she continues her training. Gradually the rehabilitation programme is expanded from single contractions in her legs and feet to complete movement patterns that are then generalized and aligned step-by-step with normal daily functioning. This last phase only begins when she has complete control over all the muscle groups in her legs.

\subsubsection{Psychotherapy: discussing somatization and trauma}

By way of recording complaints and keeping track of her exercise therapy results, Mrs Jones learns to see the relationship among tensionprovoking experiences better in the home situation or during the treatment, and her physical reaction to tension, which includes a worsening of her existing complaints or the introduction of new symptoms. This reaction pattern is discussed in light of the somatization in her history. Sensitivity, physical vulnerability and past traumatic experiences are the keys that frame the explanation of her somatization. During the course of this expressive work, Mrs Jones, in the presence of her husband, releases her anger about her past by burning a mock childhood house that she had constructed in creative therapy.

\subsubsection{Returning to normal activities without the symptoms}

A few family sessions are devoted to helping Mrs Jones re-assume her proper place in the home. Family members speak openly about their often-ambivalent feelings regarding their mother's sickness, and about the consequences it has had for them. The mere fact that Mrs. Jones is better forces family members to change routines.

\subsubsection{Outcome}

After 4 months of treatment, Mrs Jones is released from inpatient care. She is assigned to outpatient aftercare for 2 years. During outpatient care she develops a psychogenic aphonia in reaction to tensions with her youngest daughter. She decides to use her self-hypnosis techniques to re-establish her ability to speak clearly. She is successful. At 2-year followup Mrs Jones is walking regularly, sometimes with, and sometimes without, a cane.

\subsection{Case 2. A combination of a symptomatic approach using catalepsy and exposure and an insight-oriented approach using revivification}

\subsubsection{Assessment phase}

Mrs Allen is a divorced 48-year-old nurse who presents with a 3 -year history of shaking and rotating movements of her head and right arm that occur in sudden episodes. She reports that these movements are out of her control.

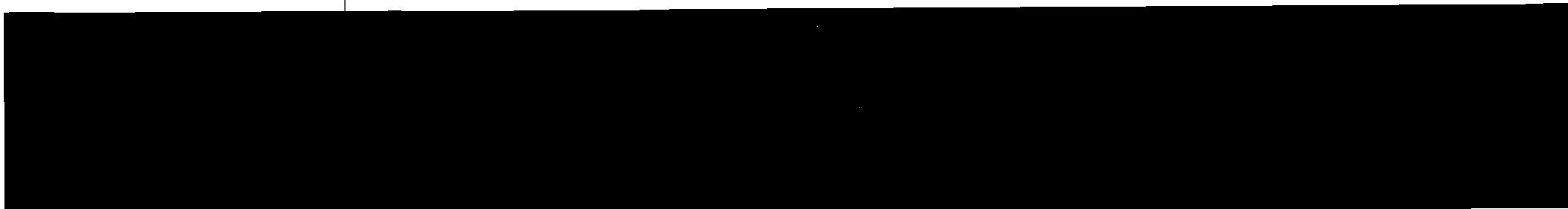


In addition, she walks bent-over, which she associates with back and neck pain. Mrs Allen easily loses her balance and she falls on a daily basis. Furthermore, she has a noticeable speech disorder, slurring her words somewhat. Mrs Allen is either in a wheelchair or walks with the aid of a walker (zimmer frame). She can no longer perform her work and is on disability.

Two years before the appearance of the complaints, Mrs Allen discovered that her husband had been having a long-term extramarital affair, and had fathered a 15-year-old child. With this discovery, Mrs Allen's relationship with her husband worsened. For a long time during her marriage she was violently abused. Her husband would beat her around the head and shoulders. Mrs Allen was ashamed of her symptoms and gradually withdrew socially, having contact only with her brother who supported her as best he could.

Assessment revealed Mrs Allen to be a good hypnotic subject ( $\mathrm{SHCS}=4$ ). She was hypothesized to be sensitive to the automatic activation of the cognitive and somatosensory representations associated with the traumatic events, e.g. the physical abuse by her ex-husband and his verbal threats. Other maintaining factors were her social phobic complaints and social isolation.

\subsubsection{Consultation}

During the consultation, Mrs Allen receives the following hypothetical but plausible rationale for her complaints:

Happily, the examination shows that your muscles and nerve paths are in good order, but your locomotion has been disrupted. Your physical movements seem to have a life of their own. You do not have full conscious control over movement any more and you are not able to calm your body down when you want to. We know that your complaints were caused during a long period in which you were under a lot of pressure because there were a lot of traumatic experiences in your relationship with your ex-husband. It was then necessary for you to protect yourself physically from him. You consciously reacted to your abuse with this protection pattern. You bowed down and protected your head with your right arm. Because this pattern of movement was repeated over and over again in a context of fear, this movement was of vital importance for you.
It is possible that it has become an automatic ingrained response and reveals itself as a kind of reflex whenever the tension increases. This occurs regardless of the fact that there is currently no direct physical danger in your life. We understand that you are not consciously aware why you are having symptoms. We have seen these reactions in the animal kingdom. A famous example of this is the phenomenon of head-withdrawal. When an animal has been regularly hit in the past, it always ducks away even in safe situations when someone with a raised hand approaches them quickly.

Everything that has happened to you had not only physical consequences for you, but also psychological consequences. That is why you feel more anxiety and are less sure of yourself, and you don't dare leave the house as much. You have been avoiding social situations and find yourself in a vicious circle through which your world is getting smaller and smaller. Attention will be given to these facets in your treatment. Do you recognize these things in yourself?

The treatment plan contains the following: gaining insight into how the movements began and discussing the important experiences from her history (hypnosis/psychotherapy); an exercise program to learn how to re-gain control of the movements (hypnosis/psychotherapy); and participation in a group therapy program to improve her assertiveness and developing social contacts and activities.

\subsubsection{Hypnosis and psychotherapy}

First, Mrs Allen becomes familiar with hypnosis and autohypnosis (induction; deduction; deepening). She also practices with audiotaped ego-strengthening exercises, and in hypnosis she creates a symbolic 'safe place' for herself where she can go when she needs it. Then, age regression is used in order explore the emotions associated with the symptoms. To help Mrs Allen become accustomed to reflecting on the past in hypnosis, the therapist suggests she return to pleasant and positive events in her life. During hypnosis she reflects on incidents of being physically abused by her ex-husband. She remembers an argument about the extramarital affair. Her ex-husband hits her on the head several times. While in hypnosis Mrs Allen describes being very anxious; she tries to protect 
oecome an automatic eals itself as a kind of increases. This occurs there is currently no ur life. We understand ly aware why you are seen these reactions in ous example of this is withdrawal. When an it in the past, it always rations when someone es them quickly.

ed to you had not only u, but also psychologi$y$ you feel more anxiety ind you don't dare leave oeen avoiding social sita vicious circle through g smaller and smaller. ese facets in your treatthings in yourself?

tains the following: e movements began nt experiences from notherapy); an exerto re-gain control of osychotherapy); and therapy program ess and developing

\section{psychotherapy}

miliar with hypnosis action; deduction; ces with audiotaped , and in hypnosis she ce' for herself where it. Then, age regresa the emotions assoTo help Mrs Allen acting on the past in ggests she return to $s$ in her life. During incidents of being r ex-husband. She out the extramarital ts her on the head yppnosis Mrs Allen s; she tries to protect herself by holding her arms to her head and turning her head away. She starts reacting with the same movements that burden her. The therapist decides to utilize the situation therapeutically and describes what he sees happening, and he re-labels her behavior in a positive sense:

You duck and try to protect yourself against the strikes that you receive. This was the only way you were able to protect yourself from your ex-husband's physical overpowering, but at the same time you resist with all of your strength. The severity of your movements shows how great your strength and resistance were against the negative approach of your ex-husband.

The therapist encourages Mrs Allen to express her emotions and to say to her ex-husband what she thinks of him. Then the suggestion is given that her muscles can relax afterwards and that calmness can come to her body. Eventually the movements calm down and finally cease. The therapist then gives a three-part post-hypnotic suggestion: (1) she now knows what the movements represent; (2) she has now experienced how decisive and strong she actually is; and (3) the exercise program can teach her how to regain the control over her muscle movements.

The exercise program consists of learning catalepsy (see p. 631). First the therapist teaches Mrs Allan catalepsy of the arm. Achieving this is complimented and she is asked to direct her attention to how the sensation of catalepsy feels and to store this information in her memory so that she can invoke these experiences in hypnosis (i.e. cue conditioning for rapid procedure). Afterwards, the catalepsy is discontinued by shaking the arm. This exercise is practiced a number of times until Mrs Allen succeeds in inducing the catalepsy in a very short time. Then she practices with the left arm and with both arms.

Next Mrs Allen practices with this method when her complaints are actually present, first together with the therapist and then independently. When she is able to sit sufficiently calmly for a long enough time, a self-control procedure is practiced, the so-called 1-2-3 technique. This technique reverts back to what she had practiced earlier, namely the cue conditioning for rapid procedure. The therapist practices with Mrs Allen while both are standing. He supports her shaking arm and wrist, and extends the arm until it is in a horizontal position. Then he asks Mrs Allen to go into hypnosis and to concentrate on the sensations of catalepsy with the following suggestions: (1) concentrate on your shoulder and on the sensation of catalepsy: calm, rest, control; (2) let that feeling flow through to your elbow: calm, rest, control; and (3) let that feeling flow through to your hand: calm, rest, control. Then the therapist guides the arm down until it hangs limply, and the procedure is practiced again. The procedure is repeated every time the arm or hand shakes or trembles until she restores calm. Through this, Mrs Allen also gains more control when performing normal daily movements. Gradually an attitude of self-efficacy develops where Mrs Allen has a quiet confidence that she can master the symptoms.

Eventually, Mrs Allen practices with small role-plays to retain the catalepsy in more difficult situations such as with open eyes, while talking with the therapist, in the home situation and in public places. The 1-2-3 technique is repeated each time she begins to shake. In this way she learns to be in control of her complaints anywhere she is, and to intervene early, when there is only a glimmer of a problem.

During the therapy sessions, the therapist found it important to be aware of Ms Allen's breathing. There is often hyperventilation or shallow breathing associated with the motor symptoms. Suggestions to breathe deeply and to allow for breathing from the stomach are effective when Mrs Allen masters the method she practices at home. With assistance, and with gradual exposure to social situations, Mrs Allen succeeds in going outside again and visiting people.

\subsubsection{Outcome}

Near the end of the 3-month inpatient treatment, and merging into the outpatient therapy, Mrs Allen's gradually returns to daily life, spending more and more time at home. She continues to practice hypnosis intensively at home. She is prudently vigilant for difficult or burdening situations which might trigger symptoms. She does not return to work, but she does do volunteer work for a few half-days 
during the week. This gives her the freedom that she needs. Her slurred speech has improved 75 percent without having paid any specific attention to it in treatment. The intervals between her aftercare appointments are continually extended and are finalized after 6 months. At one year follow-up, her treatment gains were maintained.

\subsection{Discussion and conclusions}

The main purpose of this chapter was to discuss a comprehensive protocol for the treatment of $C D$ and SD, including the use of hypnotic techniques Several theoretical models and neurophysiological studies emphasizing the parallel between hypnotic and conversion phenomena support the use of hypnosis in the treatment of CD. Group studies as well as clinical case studies support that notion that hypnosis can be helpful for some patients suffering from CD. For these patients, customized hypnotic techniques appear to help restore motor control via indirect and direct suggestions

Although hypnosis was not identified as a necessary factor in the treatment model described in this chapter, the comprehensive treatment program as a whole appeared to be highly effective. These findings are in line with the findings from a review by Wade (2001) indicating that a multidisciplinary rehabilitation approach with several simultaneous interventions may be most successful. Such an eclectic approach is consistent with the fact that CD and SD constitute a heterogeneous group with differing etiological backgrounds. The argument that CD should be treated as a symptom rather than a primary diagnosis appears to be quite valid. Although primary attention should be paid to symptom reduction within all treatment strategies, comorbidity should also determine the specific choice of treatment or combination of treatment strategies. For example, patients having SD with a long-standing history of conversion symptoms combined with pain require different treatment than SD patients having a history where sexual and/or physical abuse predominated.
Another complicating factor in the treatment of $\mathrm{CD}$ is that the connection between conversion symptoms and psychological triggers is often clear. When this is the case, our default option is to focus on the physiological, social and psychological consequences of the symptoms. The physiotherapeutic treatment takes the lead role, and the psychotherapeutic interventions are mainly geared towards breaking through the social and psychological barriers which maintain the symptoms.

\section{References}

Agras, S., Leitenberg, H., Barlow, D. H. and Thomson, L. (1969) Instructions and reinforcement in the modification of neurotic behavior. American Journal of Psychiatry, 125: 14335-1439.

Alper, K. Devinsky, O., Perrine, K., Vazquez, B. and Luciano, D. (1993) Nonepileptic seizures and childhood sexual and physical abuse. Neurology, 43: 1950-1953.

American Psychiatric Association (1994) Diagnostic and Statistical Mnual of Mental Sisorders, 4 th edn. American Psychiatric Association, Washington, DC.

Bendefeldt, F., Miller, L. L. and Ludwig, A. M. (1976) Cognitive performance in conversion hysteria. Archives of General Psychiatry, 33: 1250-1254.

Bernstein, E. and Putman, F. W. (1986) Development, reliability and validity of a dissociation scale. Journal of Nervous And Mental Disease, 147, 727-735.

Betts, T. and Boden, S. ( i992) Diagnosis, management and prognosis of a group of 128 patients with non-epileptic attack disorder. Part 1I. Previous childhood sexual abuse in the aetiology of these disorders. Seizure, $1: 27-32$.

Binzer, M. and Eisennann, M. (1998) Childhood experiences and personality traits in patients with motor conversion symptoms. Acta Psychiatrica Scandinavia, 98, 288-295.

Binzer, M., Andersen, P. M. and Kullgren, G. (1997) Clinical characteristics of patients with motor disability due to conversion disorder: a prospective control group study. Journal of Neurology Neurosurgery and Psychiatry, 63: 63-68.

Bliss, E. L. (1984) Hysteria and hypnosis. Journal of Nervous and Mental Disease, 172: 203-206.

Brady, J. P. and Lind, D. L. (1961) Experimental analysis of hysterical blindness. Archives of General Psychiatry, 4: 331-339.

Brewin, C. R. (2003) Post-traumatic Stress Disorder. Yale University Press. New Haven, CT.

Bowman, E. S. (1993) Etiology and clinical course of pseudoseizures: relationship to trauma, depression and dissociation. Psychosomatics, 34: 333-342.

Bowman, E, S. and Markand, O. M. (1995) Psychiatric diagnosis of pseudoseizure patients. Epilepsia, 36: \$173.

Brown, R. J. (2004) Psychological mechanisms of medically unexplained symptoms: an integrative conceptual model. Psychological Bulletin, 130: 793-812. 
ig factor in the treatment nection between converpsychological triggers is $s$ is the case, our default the physiological, social isequences of the symppeutic treatment takes the chotherapeutic intervenared towards breaking id psychological barriers mptoms.

rlow, D. H. and Thomson, $\mathrm{d}$ reinforcement in the behavior. American Journal $-1439$.

ine, K., Vazquez, B. arrd oileptic seizures and childhood Neurology, 43: 1950-1953. ation (1994) Diagnostic and al Sisorders, 4th edn. American Vashingtou, DC. nd Ludwig, A. M. (1976) conversion hysteria. Archives $1250-1254$.

W. (1986) Development, a dissociation scale. Journal of ase, $147,727-735$.

e) Diagnosis, management and 28 patients with non-epileptic revious childhood sexual abuse lisorders. Seizure, 1:27-32. (1998) Childhood ity traits in patients with motor ta Psychiatrica Scandinavia,

and Kullgren, G. (1997) Clinical with motor disability due to ospective control group study. cosurgery and Psychiatry,

nd hypnosis. Journal of Nervous 203-206.

961) Experimental analysis of ives of General Psychiatry,

umatic Stress Disorder. $\checkmark$ Haven, CT.

gy and clinical course of iip to trauma, depression and ics, 34: 333-342.

O. M. (1995) Psychiatric e patients. Epilepsia, 36: $\$ 173$. gical mechanisms of medically n integrative conceptual tin, 130: 793-812
Brown, R. J., Schrag, A. and Trinible, M. R. (2005) Dissociation, childhood interpersonal tralma, and family functioning in patients with somatization disorder. American Journal of Psychiatry, 162: 899-905.

Bryant, R. A. and McConkey, K. M. (1989) Visual conversion disorder: a case analysis of the influence of visual information. Joumal of Abnormal Psychology, 98: 326-329.

Conrad, P. L. (1985) The hypnotic treatment of intention tremor and muscle spasm. Australian Joumal of Clinical and Experimental Hypnosis, 13: 121-128.

Crimlisk, H. L., Bhatiâ, K., Cope, H., David, A Marsden, C. D. and Ron, M. A. (1998) Slater revisited: 6 year follow up of patients with medically unexplained motor symptoms. British Medical Journal, 316: 582-586.

De Haan, E and Bergsnıa, C. (2002) De behandeling van een meisje met een conversieve blindheid. Kind en adolescent praktijk, 2: 40-45.

De Lange, F. P., Roelofs, K. and Toni, 1. (2007) Increased self-monitoring during imagined movements in conversion paralysis. Netiropsychologia, 45: 2051-2058.

Drost, H. A. (1996) Stem en Spraakstoornissen. pp. 75-87. Stichting Klinische Foniatrie, Woubrugge.

Erickson, M. H. (1980) Innovative hypnotherapy. In E. L. Rossi (ed.) The Collected Papers of Milton H. Erickson, Vol. IV, pp. 177-182. Irvington Publishers, New York,

Factor, S. A., Podskalny, G. 1). and Molho, E. S. (1995) Psychogenic movement disorders: frecuency, clinical profile and characteristics. Journal of Neurology, Neurosurgery and Psychiatry, 59: 406-412.

Fukuda, M., Hata, A. and Niwa, S. (1996) Event-related potential correlates of functional hearing loss: reduced $\mathrm{P} 3$ amplitude preserved $\mathrm{N} 1$ and $\mathrm{N} 2$ components in a unilateral case. Newropsychiatry and Clinical Neuroscience, 50: 85-87.

Garfield, S. L. (1994) Research on client variables in psychotherapy. In A. E. Bergin and S. L. Garfield (ed.) Handbook of Psychotherapy and Behavior Change, pp. 190-228. Wiley, New York.

Halligan, P. W., Athwal, B. S., Oakley, D. A. and Frackowiak, R. S. J. (2000) Imaging hypnotic paralysis: implications for conversion hysteria, Lancet, 355: 986-987.

Halligan, P., Bass, C. and Marshall, J. (2001) Contemporary Approaches to the Study of Hysteria: Clinical and Theoretical Perspectives, pp. 283-297. Oxford University Press, Oxford.

Hersen, M., Gullick, E. L., Matherne, M. and Harbert, T. L. (1972) Instructions and reinforcement in the nodification of a conversion reaction. Psychological Reports, 1: 719-722.

Hilgard, E. R. (1977) Divided Consciousness: Multiple Controls in Human Thought and Action. Wiley, New York.

Hoogduin, C. A. L, and Van Dyck, R. (1992) Open trial with patients with conversion paralysis: results and follow-up. In W. Bongartz (ed.) Hyprosis: 175 Years after Mestner; Recent Developmenls in Theory and Application, pp. 411-419. Universitätsverlag, Konstanz.

Hoogduin, C. A. L. and Van Dyck, R. (1990) On the hypnotherapeutic treatment of motor conversion disorders. Swedish Journal of Hypnosis and Psychosomatic Medicine, 17: 214-220.
Hoogduin, C. A. L., Akkermans, M., Oudshoorn, D. N. and Reinders, M. (1993) Hypnotherapy and contractures of the hand. American Journal of Clinical Hypnosis, 36: 106-112.

Hoogduin. C. A. L., Moene, F. C., Näring, G., Sonneveld, J. and Brans, H. (1996) Insultprovocatie bij de diagnostiek van conversiestoornis met toevallem. Tijdschrift voor Directieve Therapie, 4: 371-385.

Janet, P. (1907) The Major Symptoms of Hysteria. MacMillan, New York.

Janet. P. $(1925,1976)$ Psychological Healing, Vol. 1 (2 vols). Macmillan Reprint, Arno Press, New York.

Kallman, W. M., Hersen, M. and O'Toole, D. H. (1975) The use of social reinforcement in a case of conversion reaction. Behavior Therapy, 6:411-413.

Kihlstrom, J. F. (1992) Dissociative and conversion disorders. In D. J. Stein and J. E. Young (ed.) Cognitive Science and Clinical Disorders, pp. 247-270. Academic Press, San Diego.

Kop, P. F. M., Van der Heijden, H. P., Hoogduin, C. A. L. and Schaap, C. P. D. R. (1995) Operant procedures applied to a conversion disorder. Clinical Psychology and Psychotherapy, ]: 59-66.

Kroger, W. S. and Fezler, W. D. (1976) Hypnosis and Behavior Modification: Imagery Conditioning, pp. 289-295. Lippincott Company, Philadelphia.

Kuyk, J., Spinhoven, P., Van Emde Boas, W. and Van Dyck, R. (1999) Dissociation in temporal lobe epilepsy and pseudo-epileptic seizure patients. Journal of Nervous and Mental Disease, 187: 713-720.

Lauerma, H. (1993) Nocturnal limb movements in conversion paralysis. Journal of Nervous and Mental Disease, 181: 707-708.

Litwin, R. and Cardeña, E. (2000) Demographic and seizure variables, but not hypnotizability or dissociation, differentiated psychogenic from organic seizures. Journal of Trauma and Dissociation, 1: 99-122.

Lorenz, J., Kunze, K. and Bromm, B. (1998) Differentiation of conversive sensory loss and malingering by P300 in a modified oddball task. NeuroReport, 9: 187-191.

Ludwig, A. M. (1972) Hysteria: a neurobiological theory. Archives of General Psychiatry, 27: 771-777.

Mace, C. J. and Trimble, M. R. (1996) Ten-year prognosis of conversion disorder. British Journal of Psychiatry, 169: $282-288$

Marsden, C. D. (1986) Hysteria-a neurologist view. Psychological Medicine, 16: 277-288.

Marshall, J. C., Halligan, P. W., Fink, G. R., Wade, D. T. and Frackowiak, R.S. (1997) The functional anatomy of a hysterical paralysis. Cognition, 64: B1-B8.

MoNally, R. J. (2003) Remembering Trauma. The Belknap Press of Harvard University Press, Cambridge, MA.

Merskey, H. (1979) The Analysis of Hysteria. Balliere, Tindall and Cassell, London.

Moene, F. C. (2003c) Aanvalsgewijs optredende dissociatieve klachten. In $\mathrm{O}$. van der Hart (ed.) Trauma, Dissociatie en Hypnose, handboek, Deel 2, Hoofdstuk 11. Swets and Zeitlinger, Amsterdam pp.335-356.

Moene, F. C. and Hoogduin, C. A.L. (1999) The creative use of unexpected responses in de hypnotherapy of patients with conversion disorders. International Journal of Clinical and Experimental Hypnosis, 47: 209-227. 
Moene, F. C. and Rümke, M. (2004) Behandeling van de Conversiestoornis. Praktiikreeks Gedragstherapie, deel 20. Bohn Stafleu Van Loghum, Houten.

Moene, F. C., Hoogduin, C. A.1. and Van Dyck, R. (1998) The inpatient treatment of patients suffering from (motor) conversion symptoms: a description of eight cases. International Journal of Clinicai and Experimental Hypnosis, 46: 171-190.

Moene, F. C., Spinhoven, Ph., Hoogduin, C. A. L. and Van Dyck, R. (2001) Prediction of outcone in patients with motor conversion disorder, treated with hypnosis and a multimethod treatment program. In F. C. Moene (ed.) Hypnosis and Conversion Disorder: Assessment and Treatment Isstes, pp. 157-168. Cure and Care Publishers, Zeist.

Moene, F. C., Spinhoven, Ph., Hoogduin, C. A. L. and Van Dyck, R. (2002) A randomized controlled clinical trial on the additional effect of hypnosis in a comprehensive treatment programme in patients with conversion disorder of the notor type. Psychotherapy and Psychosomatics, 71:66-76.

Moene, F. C., Rünke, M. and Jongerius, A. M. M. (2003a) Behandeling van de conversiestoornis. In C. van der Feltz-Cornelis and H. van der Horst (ed.) Handboek Somatisatie: Lichamelijk Omerklaarde Klachten in de Eerste en Tweede Lijn, pp. 221-232. De Tijdstroom, Utrecht.

Moene, F. C., Spinhoven, Ph., Hoogduin, C. A.L. and Van Dyck, R. (2003b) A randomized controlled clinical trial of a hypnosis-based treatment for patients with conversion. International Jowrnal of Clinical and Experimental Hypnosis, 51: 29-51.

Montgomery, J. M. and Espie, C. A. (1986) Behavioral management of hysterical pseudoseizures. Journal of Behavior Psychotherapy, 14: 334-340.

Morgan, A. H. and Hilgard, E. R. (1974) The Stanford Clinical Scale for Adults. American Journal of Clinical Hypnosis, 21: 134-147.

Morrison, J. (1989) Childhood sexulal histories of women with somatization disorder. American Journal of Psychiatry, 146: 239-241.

Munford, P. R. and Paz, G. (1978) Differential attention in the treatment of astasia-abasia. Journal of Behavior Therapy and Experimental Psychatry, 9: 369-371.

Nehmia, J. C. (1991) Dissociation, conversion and somatization. In A. Tasman and S. M. Goldfinger (ed.) American Psychiatric Press Review, 10, pp. 248--260. American Psychiatric Association, Washington, DC.

Norman, D.A. and Shallice, T. (1986) Attention to action: willed and automatic control of behavior. In R. J. Davidson, G. E. Schwartz and D. Shapiro (ed.) Corsciousness and Self-regulation, 4. Advances in Research and Theory, pp. 1-18. Plenum Press, New York.

Oakley, D. A. (1999a) Hypnosis and conversion hysteria: a unifying model. Cognitive Neuropsychiatry, 4: 243-265.

Oakley, D. A. (1999b) Hypnosis and consciousness: a structural model. Contemporary Hypnosis, 16: 215-223.

Oakley, D. A. (2001) Hypnosis and suggestion in the treatment of hysteria. In P. W. Halligan, C. Bass and J. C. Marshall (ed.) Contemporary Approaches to the Study of Hysteria: Clinical and Theoretical Perspectives, pp. 312-330. Oxford University Press, New York.
Ohno, Y., Mineyasu, S., Takeya, T., Akagi, M., Tanaka, Y. and Ikemi, Y. (1974) The treatment of hysterical blindness by behavior therapy. Psychosomatics, 15: 79-82.

Oyen, F. and Spinhoven, Ph. (1983) Nederlandse bewerking van de SHCS. Tijdschrift voor Directieve Therapie, 2: $155-172$.

Patterson, R. B. (1980) Hypnotherapy of hysterical monocular blindness: a case report. American Journal of Clinical Hypnosis, 23: 119-121.

Putnam, F. W. (1989) Pierre lanet and modern views of dissociation. Journal of Traumatic Stress, 2: 413-429.

Roelofs, K., Näring, G. W. B., Keijsers, G. P. J., Hoogduin, C. A. L., Van Galen, G. P, and Maris, E. (2001) Motor imagery in conversion paralysis. Cognitive Neuropsychiatry, 6:21-40.

Roelofs, K., Keijsers, G. P. J., Hoogduin, C. A. I., Näring, G.W. B. and Moene, F. C. (2002a) Childhood abuse in patients with conversion disorder. American Journal of Psychiatry, 159: 1908-1913.

Roelofs, K., Hoogduin, C. A. L., Keijsers, G. P. J., Näring, G. W. B., Moene, F. C. and Sandijck, P. (2002b) Hypnotic susceptibility in patients with conversion diserder. Journal of Abnormal Psychology, 3: 390-395

Roelofs, K., Van Galen, G. P., Keijsers, G. P. J. and Hoogduin, C. A. I. (2002c) Motor initiation and motor execution in patients with conversion paralysis. Acta Psychologica, 110: 21-34.

Roelofs, K., Hoogduin, C. A. L. and Keijsers, G. P. J. (2002d) Motor imagery in hypnotic paralysis. International Journal of Clinical and Experimental Hypnosis, 50: 51-66́.

Roelofs, K., Van Galen, G. P., Eling, P., Keijsers, G. P. J. and Hoogduin, C. A. L. (2003) Endogenous and exogenous spatial attention in patients with conversion paresis. Cognitive Neuropsychology, 20: 733-745.

Roelofs, K., Spinhoven, Ph., Sandijck, P., Moene, F. C. and Hoogduin, C. A. L. (2005) The impact of early trauma and later life-events on symptom severity in conversion disorder. Journal of Nervous and Mental Disease, 193: 508-514.

Roelofs, K., de Bruijn, E. R. A. and Van Galen, G. P. (2007) Hypersensitivity to conflict in conversion paralysis. An event-related potential study. Biological Psychology, 71: $316-325$

Ron, M. A. (1994) Somatisation in neurological practice. Journal of Neurology, Newrosurgery, and Psychiatry, 57: 1161-1164.

Ron, M.A. (2001) The prognosis of hysteria/somatization disorder. In P. W. Halligan, C. Bass and J. Marshall (ed.) Contemporary Approaches to the Study of Hysteria: Clinical and Theoretical Perspectives, pp. 271-282. Oxford University Press, Oxford.

Roy, A. (1979) Hysteria: a case note study. Canadian Journal of Psychiatry, 24:157.

Sacejdote, P. (1970) Theory and practice of pain control in malignancy and other protracted or recurring painful illnesses. International Journal of Clinical and Experimental Hypnosis, 18: 160-180. 
eya, T., Akagi, M., Tanaka, Y. treatment of hysterical erapy. Psychosomatics,

(1983) Nederlandse bewerking voor Directieve Therapie,

notherapy of hysterical ase report. American Journal of $-121$.

Janet and modern views of raumatic Stress, 2: 413-429.

., Keijsers, G. P. J.,

Galen, G. P. and Maris, E.

conversion paralysis.

y, $6: 21-40$.

Hoogduin, C. A. L., ne, F. C. (2002a) Childhood nversion disorder. hiatry, 159: 1908-1913.

. L., Keijsers, G. P. J. F. C. and Sandijck, P. (2002b) n patients with conversion rmal Psychology,

Keijsers, G. P. J. and c) Motor initiation and motor h conversion paralysis. $-34$.

L. and Keijsers, G. P. J. (2002d) tic paralysis. International perimental Hypnosis,

, Eling, P., Keijsers, G. P. J. and ) Endogenous and exogenous ats with conversion paresis. $y, 20: 733-745$.

Sandijck, P., Moene, F. C. and ) The impact of early trauma mptom severity in conversion us and Mental Disease,

4. and Van Galen, G. P. (2007) ct in conversion paralysis. ll study. Biological Psychology,

tion in neurological practice. rosurgery, and Psychiatry,

nosis of hysteria/somatization 1, C. Bass and J. Marshall (ed.) sto the Study of Hysteria: erspectives, pp. 271-282. Oxford.

se note study. Canadian 157.

and practice of pain control in tracted or recurring painful irnal of Clinical and 3: $160-180$.
Sackheim, H. A., Nordlie, J. W. and Gur, R. C. (1979) A model of hysterical and hypnotic blindness: cognition, motivation and awareness. Journal of Abnormal Psychology, 88: 474-489.

Salmon, P., Suad, M., Al-Marzooqi, S. M., Baker, G. and Reilly, J. (2003) Childhood family dysfunction and associated abuse in patients with nonepileptic seizures: towards a causal model. Psychosomatic Medicine, 65: 695-700.

Spence, S. A, Crimlisk, H. L., Cope, H., Ron, M. A. and Grasby, P. M. (2000) Discrete neurophysiological correlates in prefrontal cortex during hysterical and feigned disorder of movement. Lancet, 355 : 1243-1244.

Spiegel, H. and Spiegel, D. (1978) Trance and Treatment: Clinical Issues of Hypnosis, pp. 273-285. Basic Books, New York.

Spinhoven, Ph. (1989) Hypnosis and Pain Control, pp. 17-18. Academic Thesis. University of Leiden Repro, Meppel.

Tiihonen, J., Kuikka, J., Viinamaki, H., Lehtonen, J. and Partanen, J. (1995) Altered cerebrai bloodflow during hysterical paresthesia. Biological Psychiatry, 15: 134-135
Turner, S. M. and Hersen, M. (1975) Instructions and reinforcement in modification of a case of astasiaabasia. Psychological Reports, 36: 607-612.

Wade, D. T. (2001) Rehabilitation for hysterical conversion states. A critical review and conceptual reconstruction. In P. W. Halligan, C. Bass and J. Marshall (ed.) Contemporary Approaches to the Study of Hysteria: Clinical and Theoretical Perspectives, pp. 330-346. Oxford University Press, Oxford.

World Health Organization (1992) International Classification of Disorders. Clinical Descriptions and Diagnostic Guidelines. Chapter 5: Mental and Behavioral Disorders, Diagnostic Criteria and Diagnostic Guidelines. Division of Mental Health, World Health Organization, Geneva.

Wilkins, L. G. and Field, P. B. (1968) Helpless under attack: hypnotic abreaction in hysterical loss of vision. American Journal of Clinical Hypnosis, 10: 271-275.

Ziv, I., Djaldetti, R, Zoldan, Y., Avraham, M. and Melamed, E. (1998) Diagnosis of 'non-organic' limb paresis by a novel objective motor assessment: the quantitative Hoover's test. Journal of Neurology, 245: 797-802. 